\title{
Model Predicted Distribution of PM2.5 Exposure- Related Health Effects from Marcellus Shale Gas Development in Pennsylvania, 2005-2017
}

Zoya Banan ( $\sim$ zoya.banan@gmail.com )

PSE Healthy Energy https://orcid.org/0000-0003-4167-5488

Jeremy M. Gernand

Pennsylvania State University

\section{Research}

Keywords: Shale gas, Setback distance, Community air quality, Emission exposure, Health impact

Posted Date: June 10th, 2020

DOI: https://doi.org/10.21203/rs.3.rs-33668/v1

License: (c) (i) This work is licensed under a Creative Commons Attribution 4.0 International License.

Read Full License 


\section{Abstract}

\section{Background}

Development of Marcellus shale gas in recent years has turned into a public concern due to air quality changes and associated health impacts caused by emissions from shale gas development. Controlling standards and regulations were devised to provide health protection from exposure to such emissions, but health impact incidences have been reported in the areas where shale gas activities were prevailing. This study estimates the changes in expected health impacts associated to fine particulate matter $\left(\mathrm{PM}_{2.5}\right)$ emissions from shale gas development in Pennsylvania between 2005 and 2017.

\section{Methods}

The change in incidence rates is estimated using a Gaussian plume model to simulate $\mathrm{PM}_{2.5}$ concentrations over time and distance and a health risk model to calculate the relative risk of exposure associated with different concentration levels.

\section{Results}

Simulation results indicate that $\mathrm{PM}_{2.5}$ emissions from shale gas development could increase the incidence of health outcomes at specific locations over the studied timespan and in case of asthma, this increase could be as high as 20,411 persons over 13-years.

\section{Conclusion}

This study identifies the areas in Pennsylvania where more health risk assessment could be prioritized. An effective health-governing regulation should account for level of development activities as well as spatial characteristics (i.e., climate and population) of their vicinity to successfully provide health protection from air pollutants caused by shale gas development.

\section{Introduction}

The technological innovations in drilling and hydraulic fracturing led to a growing rate of shale gas production in Pennsylvania in the beginning of 21 st century. According to the US Energy Information Administration (EIA), production from shale gas was 1.1 trillion cubic feet in 2011 and it increased to more than 5 trillion cubic feet in 2016 (EIA - Shale gas production, 2019). While shale gas supports energy security, provides fewer negative environmental impacts than other fossil fuels such as coal, and boosts the local economy, it may yet result in environmental degradation and net economic losses if not done properly (Sovacool, 2014).

Jaramillo and Muller (2016) listed Pennsylvania with Ohio and Indiana as the U.S. states with the highest annual monetary damages due to exposure to air pollutants from energy production. This study 
per one extra ton of $\mathrm{PM}_{2.5}$ emissions from 2005 to 2011 (Jaramillo and Muller, 2016). Moreover, Litovitz et al. (2013) estimated the monetary damages of $\$ 2.2$ to $\$ 4.7$ million in association with shale gas development at the regional level.

Total emissions in areas highly concentrated with shale gas development may lead to concentrations higher than the EPA National Ambient Air Quality Standards (Banan and Gernand, 2018), and recorded data show that in some cases, concentrations increased up to 20 to 40 times higher than the permitted level (Sovacool, 2014). State and local governments designate the minimum distance between a shale gas wellsite and any residential building (known as setback distance) to control the associated health risks from emissions due to shale gas activities and to protect public safety (McKenzie et al., 2016). However, studies showed that setback policies were not successful in achieving their purpose to the fullest (Haley et al., 2016; Banan and Gernand, 2018).

Research shows an association between health risks and air pollutants originating from shale gas development (Shonkoff et al., 2014). Fine particulate matter $\left(\mathrm{PM}_{2.5}\right)$ is one of these pollutants (Shonkoff et al., 2014) whose health burden is known as a serious health concern around the world (WHO, 2007). Diesel engines and gas turbines, used during drilling and hydraulic fracturing, emit air pollutants that have shown association with increases in risk of morbidity and mortality (McKenzie et al., 2012; Shonkoff et al., 2014).

Many epidemiologic studies investigated the association between exposure to $\mathrm{PM}_{2.5}$ emissions and health effects. Based on the results, long-term ambient exposures to these emissions showed significant association with morbidity and mortality due to ischemic heart diseases (IHD) (Burnett et al., 2014; Xie et al., 2015), lung cancer (Burnett et al., 2014; Puett et al., 2014; Gharibvand et al., 2017; Liu et al., 2017; Morelli et al., 2016), circulatory diseases (Jerret et al., 2017), stroke and chronic obstructive pulmonary disease (Burnett et al., 2014; Liu et al.; 2017), and premature mortality (Lelieveld et al., 2015; Morelli et al., 2016). Epidemiological studies have also shown strong positive correlations between long-term exposure to airborne $\mathrm{PM}_{2.5}$ and cardiovascular morbidity and mortality (Haberzettl et al., 2012; Brook et al, 2011). According to Pascal et al. (2016), anthropogenic $\mathrm{PM}_{2.5}$ emissions are thought to be responsible for $9 \%$ of mortality incidences in France.

According to Werner et al. (2015), despite a lack of highly relevant evidence on association between shale gas development activities and any direct health impacts, the claim of shale gas development causing specific health outcomes might be valid if the lack of causal link is due to recent emergence of this industry. Other epidemiologic studies have demonstrated associations between these activities and nasal and sinus issues, migraine headaches, and fatigue symptoms (Tustin et al., 2017), and mild to severe asthma exacerbations (data from over 35 counties in PA) (Rasmussen et al., 2016). Weinberger et al. (2017) stated that the symptoms reported by the residents living within $1 \mathrm{~km}$ of a shale gas well in Pennsylvania were similar to the ones reported by other $\mathrm{PM}_{2.5}$ exposure studies. Results from Jemielita et al. (2015) indicates an association between unconventional gas development and an increase in Loading [MathJax]/jax/output/CommonHTML/jax.js . Also, Rabinowitz et al. (2015) claimed an association 
between natural gas drilling activities and upper respiratory health impacts based on their survey results which contained greater number of reported health symptoms by people who were living within $1 \mathrm{~km}$ from these sources compared to ones living farther away.

One common approach in the evaluation of health burdens from exposure to $\mathrm{PM}_{2.5}$ emissions is to estimate the increase in relative risk (RR) due to changes in concentrations by means of risk functions. Different studies have applied relative risk models in form of linear models (Cohen et al. 2004), integrated exposure-response (IER) models (Burnett et al. 2014; Maji et al 2018), and log-linear models (Burnett et al., 2014; RTI International, 2015; Lu et al. 2016; Pascal et al. 2016) with the latter recommended by WHO in estimation of health burdens due to air pollution (Ostro, 2004).

Risk models estimate the health risk based on pollutant exposure as their main input. Exposure changes as a function of time and location (Brown et al., 2015) and allocation of shale gas wells in a more dispersed pattern could cause a decrease of $80 \%$ or an increase of $600 \%$ in the number of unhealthy exposures based on population density within the vicinity of these sources (Banan and Gernand, 2020). Also, Morelli et al. (2016) argued that evaluating exposure risk based on emission measurements at background monitoring stations resulted in an underestimated risk value by 8 to $20 \%$. Therefore, it is important to account for spatial and temporal changes in air pollution concentrations in estimating the health risks attributed to shale gas development.

This study investigates the expected burden of disease associated with exposure to $\mathrm{PM}_{2.5}$ emissions from shale gas development in Pennsylvania between 2005 and 2017. We used a risk model to estimate the rate of health incidents based on the findings by epidemiologic studies on associated health effects to these emissions. This study contributes to the previous studies on environmental and health damages due to shale gas activities (Litovitz et al., 2013; Sovacool, 2014) by providing more spatial resolution in the overall burden of health impacts imposed by such development in the state.

\section{Methodology}

This evaluation comprises of two analytical steps. The first step is the simulation of $\mathrm{PM}_{2.5}$ concentrations originated from each developed shale gas well over the period of 2005 to 2017 in the Marcellus shale region of Pennsylvania. We identified the locations where annual mean concentration of $\mathrm{PM}_{2.5}$ changed due to shale gas development and estimated the number of people who could have experienced this exceedance. In the second step, we calculated the health risk associated to the simulated concentrations and determined the potential number of health problem cases, based on the results from epidemiological studies.

\subsection{Model}


The main model, implemented MATLAB (R2015a), is a health risk function which simulates the health risk due to exposure to $\mathrm{PM}_{2.5}$ emissions. For the purpose of this study, concentration-response function is a better method than dose-response function due to uncertainty in actual internal dose which serves as the input for the latter function. Concentration-response function (CRF) is as formulated below (Evans et al., 2013):

$$
R R_{C-C_{0}}=\exp \left[\beta\left(C-C_{0}\right)\right], \forall C \geq C_{0}(1)
$$

where $R R_{C-C_{0}}$ is relative risk at exposure $C$ compared to the reference exposure $C_{0}$, and $\beta$ represents the pollutant effect coefficient which indicates association between chronic emission exposure and cause of mortality or a disease. Coefficient $\beta$ is retrievable from epidemiological studies.

Results from CRF will be the input of the health impact function. In this study, we used a typical log-linear health impact function, introduced by Fann et al. (2012) as follows:

$$
\Delta y=y_{0}\left(R R_{C-C_{0}}-1\right) \cdot \operatorname{Pop}(2)
$$

where $\Delta y$ indicates resulting change in the number of adverse health outcomes, $y_{0}$ is the baseline incidence rate associated to reference exposure $C_{0}$, Pop is the population affected by the change in air quality.

In this evaluation, we estimate exposure $C$ and the population affected by the change in air quality Pop at each specific distance from every developed well between 2005-2017. For this purpose, we applied the Gaussian plume model developed by Banan and Gernand (2020) which simulates the concentration of non-reactive air pollutants such as primary $\mathrm{PM}_{2.5}$ within the vicinity of their source and sync the results with census data to provide an estimate of people experienced exposure to certain level of such pollutant concentrations. For the purpose of this analysis, we modified Banan and Gernand (2020) model to identify any location beyond PA's setback from each developed well where the change in $\mathrm{PM}_{2.5}$ concentrations due to emissions from shale gas development was estimated to be positive. More details on the modified Gaussian plume model used in this evaluation is available in the Additional Text File.

\subsection{Data Sources}

This study focuses on estimation of changes in the incidences of health impacts associated with residents' exposure to $\mathrm{PM}_{2.5}$ emissions from shale gas developments between 2005 and 2017 in Pennsylvania. Thus, we simulate such impacts in association with any developed well during this period of time in Marcellus shale region of Pennsylvania.

Well data comprising of location, number of wells per wellpad, and "SPUD Date" (the date that drilling Loading [MathJax]/jax/output/CommonHTML/jax.js orts by Pennsylvania Department of Environmental 
Protection (Department of Oil and Gas Reporting website, 2019). We used the wind data provided by lowa Environmental Mesonet (IEM, 2018), measured at seventeen weather monitoring stations in Pennsylvania between 2005 and 2017, comprising of hourly wind direction, wind speed, relative humidity, and cloud coverage.

Solid information is not available on the rate of pollutant emissions from shale gas development stages. We repeated the Monte Carlo simulation by Roy et al. (2014), accounting for drilling rate of $1000 \mathrm{ft} / \mathrm{day}$ and fracking rate of $1000 \mathrm{ft} /$ day in three stages estimated in literature and technical reports (McKeon, 2011; Facts about Canada's Oil and Natural Gas Industry, 2019; Coloradans for Responsible Energy Development, 2019). The final estimated mean and $95 \% \mathrm{Cl}$ for $\mathrm{PM}_{2.5}$ emission rates used in this evaluation were estimated to be $0.45(0.1-1.3)$ and $1.06(0.28-1.88) \mathrm{gr} / \mathrm{hr}$ from drilling and hydraulic fracturing, respectively (refer to Additional Text File for more details). In this manuscript, the $\mathrm{PM}_{2.5}$ concentration simulations and health risk evaluations are mainly associated to the high (97.5th percentile) emission rate value for either operation phase (unless otherwise noted). Detailed results for mean and low emission rates are available in Additional Excel File.

We used the latest U.S. Census block data (Census Data, 2010) to investigate potential number of people who might have experienced air quality changes due to emission from shale gas development. Corresponding data was population, block area, and block geographic location (latitude and longitude).

Pollutant coefficient ( $\beta$, Eq. 1$)$ and baseline incidence rate $\left(y_{0}\right.$, Eq. 2$)$ for different health outcomes are the two main inputs of our model. Epidemiologic studies have provided estimated pollutant coefficients for the health issues which evaluations show associations between exposure to $\mathrm{PM}_{2.5}$ emissions and increase in their incidence. Table-1 provides the list of pollutant coefficients and baseline incidence rates used in this evaluation. The U.S. EPA developed the environmental Benefits Mapping and Analysis Program (BenMAP) which has been used as an analytical tool by scientists, policy analysts, and decision makers for air quality management purposes and policy assessment and to estimate the human health impact associated with changes in air quality (RTI International, 2015). Therefore, we used the same reference studies included by BenMAP in order to keep the same ground for our analytical estimates as the ones used in policy and regulatory purposes before.

\section{[Table-1: Pollutant coefficients and baseline incidence rates for health impacts, attributable to hazardous level of $\mathrm{PM}_{2.5}$ emissions]}

Currently, the health effects associated with exposure to $\mathrm{PM}_{2.5}$ emissions may not be attributed to specific source or individual components of $\mathrm{PM}_{2.5}$ emissions (EPA, 2010; Burnett et al., 2014; WHO, 2007). This study estimated the health impacts based on number of available pollutant effect coefficients for any source or component of $\mathrm{PM}_{2.5}$ emissions (listed in Table-1).

\subsection{Analvsis}


This study provides an estimation of the health impacts imposed by shale gas development as a contribution to similar efforts by studies such as Litovitz et al. (2013) and Sovacool (2014). The output of our model is the estimated change in the number of health impact incidences due to exposure to $\mathrm{PM}_{2.5}$ emissions from shale gas development activities by county and year.

Assuming perfect compliance with the setback policy in Pennsylvania (152.4 m), our model indicates the points beyond this distance from wellsites with non-zero concentration. These points are specified by a grid size of 25-by-25 meters. Population density at each of the grids is estimated using Census data for the closest census block. The model assumes even distribution of population for each census block, similar to the approach previously considered by Czolowski et al. (2017). Thus, expected number of affected people is equal to the product of population density (persons per area of the block) at each grid and the grid size $\left(625 \mathrm{~m}^{2}\right)$.

For each wellpad, our model uses the "SPUD DATE" as well as the total drilled and fractured length of wells to specify the activities time window. It then uses the hourly wind data measurements at the closest weather monitoring station to that wellsite during the corresponding time window to simulate the $\mathrm{PM}_{2.5}$ concentrations at each hour of operation. The model assumes zero accumulation of emissions from hour to hour, but it accounts for accumulation of emissions dispersed from multiple sources at every hour to simulate $\mathrm{PM}_{2.5}$ concentrations at each grid.

The reference exposure ( $C_{0}$ in Eq. 1 ) at any location is assumed to be equal to the level of $\mathrm{PM}_{2.5}$ before the air quality was changed due to emissions from shale gas development. Therefore, the model estimates the increase in the incidence of any health impact from the expected number of incidences corresponding to no shale gas development in those areas. Incidence rate data was not available for all identified health impacts which were identified to be associated to chronic exposure to $\mathrm{PM}_{2.5}$ emissions. Thus, the model estimated the increase in the health impacts with available incidence rate.

For the purpose of this study, we used the unit of person-years in calculating the potential number of affected people by $\mathrm{PM}_{2.5}$ emissions from shale gas development over years. Person-years is an epidemiologic jargon which allows to accommodate for persons coming into and leaving the study when quantifying incidence rate of a health outcome. Therefore, it accounts for the possibility that same person be counted in multiple years.

Our model only accounts for emissions from diesel engines at the wellsite and does not consider emissions from trucks, fugitive dust, mineral dust from proppant handling, or road dusts. We also assumed a flat terrain (no buildings or similar structures) around the wellsite, as most of the shale gas wellsites in Pennsylvania are generally located in rural areas with few or no such a structure within their close vicinity. We assumed constant weather conditions for each hour of operation at each wellsite as well as the same hourly emission rates for drilling and hydraulic fracturing stages of all wells. The model assumes zero precipitation which is a typical assumption in Gaussian plume modeling. This study does 
duration of development operations at the wellsites, as this information is not publicly available. Such delays would extend the period of emissions being released from the diesel engines in-use and could increase the annual average concentration within the vicinity of shale gas wellsite. This increase implies higher relative risk value (Eq. 1) and therefore, greater increase in the incidence of different health impacts (Eq. 2).

\section{Results}

[Figure-1: Simulated changes in the incidence of health impacts due to shale gas activities (person). For the cases of asthma, chronic bronchitis and lung cancer, the lower and upper bounds are the estimated incidence cases based on available data for pollutant coefficients and baseline incidence rates. For other health impacts only one set of data was retrieved.]

Table-2 provides the estimated changes in the incidence of discussed health impacts at three simulated levels of emission rates during the drilling and hydraulic fracturing phases of development. The mean values and $95 \%$ confidence intervals in this table are with respect to mean emission rates and their $95 \%$ $\mathrm{Cl}$, i.e. $0.45(0.1-1.3)$ and $1.06(0.28-1.88)$ gram per hour for drilling and fracturing, respectively (refer to Additional Excel File for more detailed results).

Table-2: Simulated changes in the incidence of discussed health impacts with respect to different rates of $\mathrm{PM}_{2.5}$ emissions during shale gas development

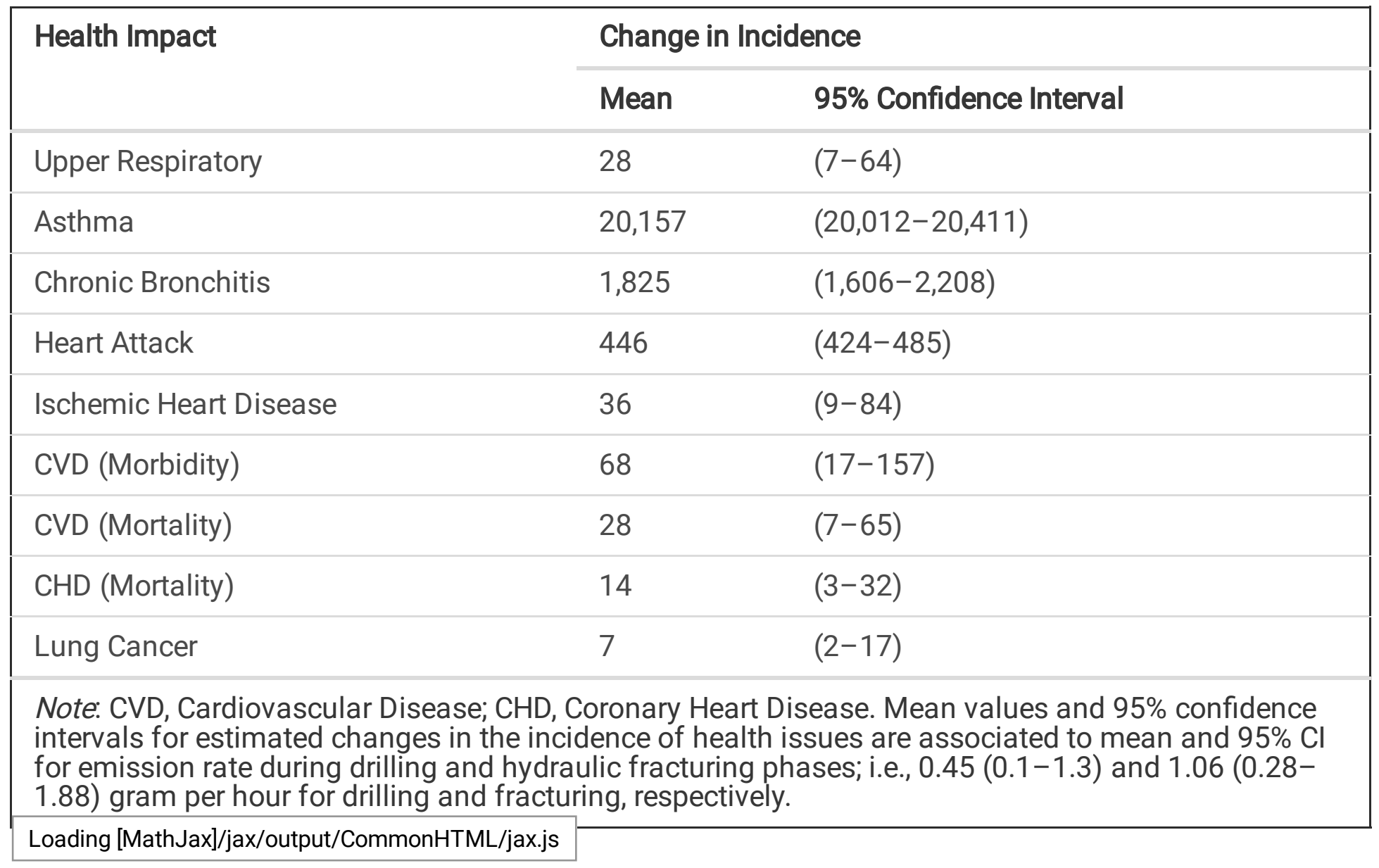


Also, Figure-2 demonstrate the impact of implementing different setback distances on the estimated change in the incidence of asthma cases due to $\mathrm{PM}_{2.5}$ emissions from shale gas development. Value at each setback level indicates the corresponding reduction in the number of incidences in Pennsylvania estimated at setback distance of $152.4 \mathrm{~m}$ from any wellsite; i.e. 20,411 persons (Figure-1).

[Figure-2: Estimated reduction in the number of asthma outcomes due to $\mathrm{PM}_{2.5}$ emissions from shale gas development at different setback distances compared to current setback distance in Pennsylvania (152.4 $\mathrm{m}$ or $500 \mathrm{ft}$.) for the case of Asthma.]

Previous studies discussed density of shale gas activities per wellsite and their proximity to residential areas as critical factors in the evaluation of individual exposures to $\mathrm{PM}_{2.5}$ emissions (Banan and Gernand, 2020; Brown et al., 2015). Figure-3 and Figure-4 demonstrate the estimated contribution of shale gas emissions to the increase in the incidence of nine health impacts over the studied time with respect to location of developments.

[Figure-3: Simulated contribution of emissions from shale gas activities to changes in incidence of mortality outcomes by county: a) Coronary heart disease (CHD), b) Cardiovascular disease (CVD), and c) Lung cancer.]

[Figure-4: Simulated contribution of emissions from shale gas activities to changes in the number of morbidity outcomes by county: a) Acute upper respiratory disease, b) Asthma, c) Chronic bronchitis, d) Cardiovascular disease (CVD), e) Heart attack, and f) Ischemic heart disease (IHD).]

Table-3: Well and population statistics of counties with the highest estimated contribution to the increase in number of morbidity or mortality outcomes. 


\begin{tabular}{|c|c|c|c|c|c|c|c|}
\hline \multirow[t]{2}{*}{ County } & \multirow{2}{*}{$\begin{array}{l}\text { Affected } \\
\text { Population } \\
\text { (person-year) }\end{array}$} & \multirow{2}{*}{$\begin{array}{l}\text { Fraction of } \\
\text { Affected } \\
\text { Population by } \\
\text { Multiple Wellsites } \\
\text { (\%) }\end{array}$} & \multicolumn{2}{|c|}{$\begin{array}{l}\text { Population } \\
\text { Density } \\
\text { (person/km²) }\end{array}$} & \multirow{2}{*}{$\begin{array}{l}\text { No. } \\
\text { of } \\
\text { Wells }\end{array}$} & \multicolumn{2}{|c|}{ Wellpad Density } \\
\hline & & & Mean & Median & & Mean & Median \\
\hline Allegheny & $2,326,990$ & 5.14 & 207.8 & 82.3 & 128 & 4.9 & 5 \\
\hline Armstrong & $1,544,606$ & 1.59 & 218.7 & 25.8 & 244 & 1.3 & 1 \\
\hline Beaver & $1,750,600$ & 12.25 & 144.8 & 36.8 & 83 & 1.9 & 1 \\
\hline Bradford & $1,395,803$ & 1.72 & 81.2 & 11.5 & 1437 & 1.9 & 1 \\
\hline Butler & $4,531,100$ & 0.51 & 79.0 & 44.5 & 568 & 2.4 & 2 \\
\hline Fayette & $3,480,000$ & 5.17 & 179.7 & 34.2 & 290 & 2 & 1 \\
\hline Greene & $1,588,924$ & 2.32 & 83.5 & 18.2 & 1246 & 3.1 & 2 \\
\hline Lycoming & $1,216,785$ & 8.89 & 41.2 & 41.2 & 958 & 2.7 & 2 \\
\hline Susquehanna & $1,841,501$ & 1.70 & 67.3 & 15.6 & 1431 & 2.3 & 2 \\
\hline Tioga & $1,456,012$ & 4.00 & 22.6 & 10.1 & 954 & 2.3 & 1 \\
\hline Washington & $4,527,606$ & 1.81 & 73.4 & 26.3 & 1702 & 3.6 & 3 \\
\hline Westmoreland & $3,815,460$ & 3.90 & 303.7 & 37.6 & 278 & 1.9 & 1 \\
\hline \multicolumn{8}{|c|}{$\begin{array}{l}\text { Note: Affected population is the simulated number of people (person-year) who experienced changes } \\
\text { in PM }{ }_{2.5} \text { concentrations due to shale gas development activities between } 2005 \text { and } 2017 \text {. The column } \\
\text { of "Fraction of Affected Population by Multiple Wellsites" lists the percentage of affected population } \\
\text { which could have experienced the exposure to PM } \mathrm{PM}_{2.5} \text { emissions from development of multiple } \\
\text { wellsites. Population density is the mean population density of the three closest census blocks within } \\
152.4 \mathrm{~m} \text { distance to each developed well in each county. }\end{array}$} \\
\hline
\end{tabular}

Butler, Fayette, Westmoreland and Allegheny are the next four counties (in decreasing order) with high shares of the estimated total number of people affected by low air quality due to shale gas development (see Additional Excel File, Table-S2 to Table-S27). Table-2 provides more details on the wellsite-specific factors that could explain the contribution of listed counties in Figure-4 to the estimated changes in incidence of associated morbidity outcomes. Corresponding population and activity statistics in these counties (Table-3) indicate that the contribution of Washington County to the simulated changes is attributable to level of activity (number of developed wells and wellpad density) as well as proximity to more populated areas. Results presented in Figure-3 and Figure-4 are based on high level of $\mathrm{PM}_{2.5}$ emission rate during drilling and hydraulic fracturing stages. Refer to the Additional Excel File, Table-S28 for corresponding estimations based on mean and low levels of $\mathrm{PM}_{2.5}$ emission rates.

The density of shale gas development in terms of the number of wells per area is found to be a Loading [MathJax]/jax/output/CommonHTML/jax.js reland and Allegheny counties. For instance, data indicate 
that $5.2 \%$ of the estimated total people affected by low air quality due to shale gas development in Fayette is attributable to the cumulative effect of emissions from these activities. In case of Butler County, the level of activity (number of developed wells and wellpad density) found to be a less significant factor, but proximity to more populated areas explains the high contribution of this county to the estimated total incidence of morbidity cases.

\section{Discussion}

Results from this study are simulation of the contribution of $\mathrm{PM}_{2.5}$ emissions from shale gas development to the increases in incidence of specific diseases. These results are consistent with the findings by Jaramillo and Muller (2016) and Litovitz et al. (2013) on the increases in the incidence of health issues due to $\mathrm{PM}_{2.5}$ emissions from shale gas development, while they add more resolutions in spatial distribution of such increase. The current analysis also estimates the incidence of specific health outcomes by county.

Our results show the inefficacy of current policies to achieve public health protection at every location, especially when accounting for accumulation of $\mathrm{PM}_{2.5}$ emissions from multiple wellsites. In the case of asthma, one of the predominate health impacts of exposure to these emissions, we estimated emissions from shale gas development wellsites to result in an increase of 20,157 (95\% Cl: 20012, 20411) incidents in Pennsylvania. The mean value of this range represents a $2.3 \%$ increase in the total cases in the state over the time period 2005-2017 (with respect to the estimated asthma cases in 2008) (Center for Disease Control and Prevention, 2019). Moreover, corresponding values for the estimated increase in mortality incidences of lung cancer $(7 ; 95 \% \mathrm{Cl}: 2,17)$ in Pennsylvania reflect an increase of $0.1 \%$ in this state.

Evaluation of estimated changes in the incidence of health outcomes with respect to location shows the spatial heterogeneity in these impacts. Results from Litovitz et al. (2013) also demonstrated spatial heterogeneity in the impacts associated with shale gas development. Our results are consistent with the counties identified by Litovitz et al. (2013) as most burdened by air pollution damages in 2011, with Washington County ranked first. From our results, part of the potential change in the incidence of associated health impacts are attributable to the counties with either higher level of shale gas development (i.e. more developed wells per wellsite or per area) (such as Washington, Bradford and Susquehanna), or higher population density within the vicinity of developments (Westmoreland).

However, there is still a considerable portion of estimated increase in health problems such as asthma in the less-populated counties (Greene) or counties with a relatively lower level of shale gas development (Allegheny), or both (Fayette). Our results indicate that estimated total change in the incidence of associated health impacts should be investigated with respect to a combination of factors (i.e. number of wells, wellpad-density, well density per area, and population density). For example, despite a lower number of developed wells in Allegheny County, a higher number of wells per wellpad and proximity of development activities to more populated areas help explain the estimated change in the incidences of ible-3). 
Contribution by other counties listed in Table-2, such as Armstrong and Beaver, is estimated to be lower, but still significant. Despite fewer developed wells in these counties, corresponding $\mathrm{PM}_{2.5}$ emissions are estimated to increase the number of asthma incidences in Armstrong and Beaver by about 860 (95\% Cl: $857,866)$ and $977(95 \% \mathrm{Cl}: 972,986)$ cases, respectively. A combination of factors could explain the outcomes in such cases. For instance, in Beaver County the cumulative emissions from multiple sources (which would lead to greater change in $\mathrm{PM}_{2.5}$ concentrations) as well as proximity to more populated areas could increase the number of asthma cases. A county-level analysis does not provide sufficient data with which to statistically evaluate the contributions of these factors and their interactions, but future analysis should continue to investigate these effects with an aim towards the amelioration of current policy.

Presented results associated with unconventional natural gas development activities over 13 years (2005 to 2017) demonstrate the potential limitations of current management of this development in safeguarding the public welfare. Other studies, such as Haley et al. (2016) and Banan and Gernand (2018), have previously discussed the insufficiency of current setback policies for shale gas wellsites to achieve compliance with EPA's standards on $\mathrm{PM}_{2.5}$ exposure. However, results presented here indicate that even though increasing setback distance would reduce the exposure of people to high $\mathrm{PM}_{2.5}$ concentrations, it does not seem to have much protective effect with respect to population health. The area experiencing low increases in concentrations is much larger and much more populated than the close-in area adjacent to the wellsites where concentrations tend to exceed NAAQS. This presents a unique environmental management challenge that could be addressed more efficiently by reducing emissions at the wellsites rather than pushing these wellsites further from occupied buildings.

Results from this study imply the need for a health protection policy which accounts for spatial characteristics within the vicinity of developed wellsites as well as the level of activities. Such a policy should consider the impact of cumulative emissions from multiple sources, even in low-populated areas (similar to the case of Beaver County). Said otherwise, a policy which sets a cap on number of wells to be developed per site and/or the minimum distance from development sites may not be sufficient to achieve health protection from $\mathrm{PM}_{2.5}$ emissions due to shale gas development in Pennsylvania.

A positive association between exposure to $\mathrm{PM}_{2.5}$ emissions and cardiovascular mortality has even been observed at $\mathrm{PM}_{2.5}$ concentrations of $8.7 \mu \mathrm{g} / \mathrm{m}^{3}$ in Canada (Crouse et al., 2012). Nevertheless, there is no evidence of a lack of adverse health impacts below a specific threshold (WHO, 2013). Therefore, we conducted this evaluation for any level of increase in $\mathrm{PM}_{2.5}$ exposure due to shale gas development activities and did not suggest that the health risk is zero at any specific concentration level. Our goal was to evaluate the effectiveness of current policy in providing public health protection and our results indicate the extra incidences of any specific health impact due to emissions from shale gas development.

There are some limitations pertaining to this evaluation. The even population distribution may reflect a rough assumption to incorporate the impact of population spatial distribution. Few studies have Loading [MathJax]/jax/output/CommonHTML/jax.js busing units) to allocate the population around oil and gas 
emission sources (Michanowicz et al. 2019; McKenzie et al. 2016). Still, data limitation on true residential locations and household population serves as an obstacle to accurately estimate the number of people who lives within the vicinity of developed wells (Michanowicz et al. 2019).

Results from this study are an estimation of changes in the incidence of health impacts due to shale gas development, based on the described associations between exposure to $\mathrm{PM}_{2.5}$ emissions and such impacts by peer-reviewed epidemiologic studies. While such estimates are made with the best methodology available, predicting effects from exposures to specific pollutants when the studied populations were exposed to complex mixtures leaves some irresolvable uncertainty. The best way to reduce such uncertainty for future research involves monitoring of exposures as they occur rather than reconstructing them from historical data and recording health effects of the affected population during and after such exposures. Such studies would be resource intensive, but this analysis presented here should offer information to enhance the feasibility of these future studies. Our results indicate that the overall impact of this industry is non-trivial, and greater scrutiny of the air quality impacts of the industry as a whole is warranted.

This study is an estimation of expected changes in the incidence of health impacts associated with fine particulate matter only and these results do not indicate the contributions of other typical emissions originating from shale gas wellsites (nitrogen oxides, volatile organic compounds, etc.) to such outcomes. Emission inventories (Litovitz et al., 2013; Roy et al., 2014) have indicated that emissions of VOCs and NOx from shale gas development could exceed PM 2.5 emissions by mass (by an order of magnitude in case of NOx), while the EPA dictates more restricted limits on these pollutants; e.g., the limit of $53 \mathrm{ppb}$ and $100 \mathrm{ppb}$ on annual and daily NOx emissions, respectively (NAAQS, 2012). Therefore, there is a significant need for future work to evaluate the impact of these emissions as well.

\section{Conclusion}

This study indicated the inadequacy of current policy to provide public health protection at all locations by estimating the increases in incidence of adverse health effects associated with $\mathrm{PM}_{2.5}$ emissions from shale gas development. Such increases are not correlated with the total number of developed wells in all locations. Rather these effects are attributable to the case of wellsites with high wellpad density or multiple wellsites with fewer wells per wellpad within a close proximity to each other being developed in more populated areas.

Results from this study show that potential changes in the incidence of health impacts are not uniform across the Marcellus shale region in Pennsylvania. There is no one specific factor that governs the pattern of these changes, and rather it is the complex combination of wellpad density, well area-density (number of wells per area), the number of developed wells, and population density that explain the differences in the changes of health impacts incidences at different locations. Therefore, an environmental policy that seeks to reduce the health burden of hazardous emissions such as $\mathrm{PM}_{2.5}$ 
resulted by shale gas development should consider spatial characteristics of the neighborhood alongside the level of activities at the future development wellsites.

\section{Declarations}

\section{Declarations}

\section{- Ethical Approval and Consent to participate}

Not applicable.

\section{- Consent for publication}

Not applicable.

\section{- Availability of data and materials}

All data generated or analyzed during this study are included in this published article and its supplementary information files. More detailed explanations and descriptions are available from the corresponding author on reasonable request.

\section{- Competing interests}

The authors declare that they have no competing interests.

\section{- Funding}

This research did not receive any specific grant from funding agencies in the public, commercial, or notfor-profit sectors.

\section{- Authors' contributions}

ZB contributed to the conceptualization and design of the work, devising the methodology, data gathering and investigation, data curation, development of the MATLAB model and conducting the scientific analysis, interpretation and evaluation of the results, and preparation and writing the original draft.

JG contributed to the conceptualization and design of the work, development of methodology, interpretation and evaluation of the results, and conducting the review and revising of the draft. JG provided the resources.

Both authors approved the submitted version of this scientific work and agreed to be personally accountable for their own contributions and to ensure that questions related to the accuracy or integrity of any part of the work, even ones in which they were not personally involved, are appropriately investigated, resolved, and the resolution documented in the literature. 


\section{- Acknowledgements}

The authors are grateful to Professor Mort D. Webster and Dr. Eugene Morgan for providing intellectual and material resources to improve this study.

\section{- Authors' information}

Zoya Banan (corresponding author) is a PhD scientist at PSE Healthy Energy, Oakland, CA 94612, USA.

Jeremy M. Gernand is an Assistant Professor of Industrial Health and Safety at the Department of Energy and Mineral Engineering, Pennsylvania State University, University Park, PA 16802, USA.

\section{References}

1. Adgate JL, Goldstein BD, McKenzie LM. Potential Public Health Hazards, Exposures and Health Effects from Unconventional Natural Gas Development. Environmental Science Technology. 2014;48:8307-20.

2. American Heart Association. 2019. https://www.ahajournals.org/; (accessed June 5, 2019).

3. American Lung Association. 2019. https://www.lung.org/our-initiatives/research/monitori.

4. ng-trends-in-lung-disease/estimated-prevalence-and-incidence-of-lung-disease/; (accessed June 5, 2019).

5. Arystanbekova NK. 2004. Application of Gaussian plume models for air pollution simulation at instantaneous emissions, Mathematics and Computers in Simulation. 67, 451-458.

6. Banan Z, Gernand JM. 2020. Emissions of Particulate Matter due to Marcellus Shale Gas Development in Pennsylvania: Mapping the Implications. In press.

7. Banan Z, Gernand JM. Evaluation of gas well setback policy in the Marcellus Shale region of Pennsylvania in relation to emissions of fine particulate matter. J Air Waste Manag Assoc. 2018;68(9):988-1000.

8. Brook RD, Bard RL, Burnett RT, Shin HH, Vette A, Croghan C, Phillips M, Rodes C, Thornburg J, Williams R. Differences in blood pressure and vascular responses associated with ambient fine particulate matter exposures measured at the personal versus community level. Occupational Environmental Medicine. 2011;68:224-30.

9. Brown DR, Lewis C, Weinberger BI. Human exposure to unconventional natural gas development: A public health demonstration of periodic high exposure to chemical mixtures in ambient air. Journal of Environmental Science Health Part A. 2015;50(5):460-72.

10. Burnett RT, Pope III, Ezzati CA, Olives M, Lim C, Mehta SS, Shin S, Singh HH, Hubbell G, Brauer B, Anderson M, Smith HR, Balmes KR, Bruce JR, Kan NG, Laden H, Prüss-Ustün F, Turner A, Gapstur MC, Diver SM, Cohen WR, A. An Integrated Risk Function for Estimating the Global Burden of Disease Attributable to Ambient Fine Particulate Matter Exposure. Environmental Health Perspective. 
11. Census Data. 2010. https://www.census.gov/geo/maps-data/data/tiger-data.html; (accessed June $5,2019)$.

12. Center for Disease Control and Prevention. 2019. https://www.cdc.gov/asthma/state.

13. profiles/Asthma_in_PA.pdf; (accessed August 27, 2019).

14. Cohen AJ, Anderson HR, Ostro B, Pandey KD, Krzyzanowski M, Ku“nzli N, Gutschmidt K, Pope CA III, Romieu I, Samet JM, Smith KR. 2004. Urban Air Pollution. Comparative Quantification of Health Risks: Global and Regional Burden of Disease Attributable to Selected Major Risk Favors (2), World Health Organization: Geneva, Switzerland. 1353-1433.

15. Coloradans for Responsible Energy Development. 2019. https://www.cred.org/fracking-frequency/; (last accessed on May 25, 2019).

16. Crouse DL, Peters PA, Donkelaar A, Goldberg MS, Villeneuve PJ, Brion O, Khan S, Atari DO, Jerrett M, Pope CA III, Brauer M, Brook JR, Martin RV, Stieb D, Burnett RT. Risk of Nonaccidental and Cardiovascular Mortality in Relation to Long-term Exposure to Low Concentrations of Fine Particulate Matter: A Canadian National-Level Cohort Study. Environmental Health Perspective. 2012;120(5):708-14.

17. Czolowski ED, Santoro RL, Srebotnjak T, Shonkoff SB. Toward Consistent Methodology to Quantify Populations in Proximity to Oil and Gas Development: A National Spatial Analysis and Review. Environmental Health Perspective. 2017;125(8):086004-1.

18. Department of Oil. and Gas Reporting website, 2018. http://www.depreportingservices.

19. state.pa.us/ReportServer/Pages/ReportViewer.aspx?/Oil_Gas/Permits_Issued_Detail; (accessed June 5, 2019).

20. Drillinginfo. 2019. https://info.drillinginfo.com/; (accessed May 20, 2019).

21. EIA - Shale gas production. 2016. http://www.eia.gov/dnav/ng/ng_prod_shalegas_s1_a.

22. htm; (accessed June 5, 2019).

23. EIA. - Shale gas proved reserves, 2016. http://www.eia.gov/dnav/ng/ng_enr_shalegas_a_.

24. epg0_r5301_bcf_a.htm; (accessed June 5, 2019).

25. EPA. 2018. https://www.epa.gov/outdoor-air-quality-data/download-daily-data; (accessed June 5, 2019).

26. EPA. Integrated Science Assessment for Particulate Matter. National Center for Environmental Assessment-RTP. Research Triangle Park: Division Office of Research and Development, U.S. Environmental Protection Agency; 2010.

27. Evans J, Donkelaar AV, Martin RV, Burnett R, Rainham DG, Birkett NJ, Krewski D. Estimates of global mortality attributable to particulate air pollution using satellite imagery. Environmental Research. 2013;120:33-42.

28. Facts about Canada's Oil and Natural Gas Industry. 2019. https://oilandgasinfo.ca/knowfracking/how-long-does-fracking-take/; (accessed May 20, 2019). 
29. Fann N, Lamson A, Wesson K, Risley D, Anenberg SC, Hubbell BJ. Estimating the National Public Health Burden Associated with Exposure to Ambient PM2.5 and Ozone. Risk Analysis. 2012;32(1):81-95.

30. Gharibvand L, Shavlik D, Ghamsary M, Beeson WL, Soret S, Knutsen R, Knutsen SF. The Association between Ambient Fine Particulate Air Pollution and Lung Cancer Incidence: Results from the AHSMOG-2 Study. Environmental Health Perspectives. 2017;125(3):378-84.

31. Glad JA, Brink LL, Talbott EO, Lee PC, Xu X, Saul M, Rager J. The Relationship of Ambient Ozone and PM2.5 Levels and Asthma Emergency Department Visits: Possible Influence of Gender and Ethnicity. Archives of Environmental Occupational Health. 2012;62(2):103-8.

32. Haberzettl P, Lee J, Duggineni D, McCracken J, Bolanowski D, O'Toole TE, Bhatnagar A, Conklin DJ. Exposure to Ambient Air Fine Particulate Matter Prevents VEGF-Induced Mobilization of Endothelial Progenitor Cells from the Bone Marrow. Environmental Health Perspectives. 2012;120(6):848-56.

33. Haley M, McCawley M, Epstein AC, Arrington B, Bjerke EF. Adequacy of Current State Setbacks for Directional High-Volume Hydraulic Fracturing in the Marcellus, Barnett, and Niobrara Shale Plays. Environmental Health Perspectives. 2016;124(9):1323-33.

34. IEM. lowa Environmental Mesonet, 2018. http://mesonet.agron.iastate.edu/request/.

35. download.phtml? network = PA_ASOS; (accessed June 5, 2019).

36. Ito K. 2003. Associations of Particulate Matter Components with Daily Mortality and Morbidity in Detroit, Michigan. Revised Analyses of Time-Series Studies of Air Pollution and Health. 143-156.

37. Jaramillo P, Muller NZ. 2016. Air pollution emissions and damages from energy production in the U.S.: 2002-2011. Energy Policy. 90, 202-211.

38. Jemielita T, Gerton GL, Neidell M, Chillrud S, Yan B, Stute M, Howarth M, Saberi P, Fausti N, Penning TM, Roy J, Propert KJ, Panettieri RA. 2015. Unconventional Gas and Oil Drilling is Associated with Increased Hospital Utilization Rates. PLOS ONE 10:7, e0131093.

39. Jerret M, Turner MC, Beckerman BS, Pope CA III, Donkelaar A, Martin RV, Serre M, Crouse D, Gapstur SM, Krewski D, Diver WR, Coogan PF, Thurston GD, Burnett RT. Comparing the Health Effects of Ambient Particulate Matter Estimated Using Ground-Based versus Remote Sensing Exposure Estimates. Environmental Health Perspectives. 2017;125(4):552-9.

40. Kaiser Family Foundation. 2019. https://www.kff.org/state-category/health-ztatus/?state=.

41. PA; (accessed June 5, 2019).

42. Krewski D, Jerrett M, Burnett RT, Ma R, Hughes E, Shi Y, Turner MC, Pope CA 3rd, Thurston G, Calle EE, Thun MJ, Beckerman B, DeLuca P, Finkelstein N, Ito K, Moore DK, Newbold KB, Ramsay T, Ross Z, Shin H, Tempalski B. 2009. Extended follow-up and spatial analysis of the American Cancer Society study linking particulate air pollution and mortality. Research Report (Health Effects Institute). 140, 5114.

43. Lelieveld J, Evans JS, Fnais M, Giannadaki D, Pozzer A. The contribution of outdoor air pollution sources to premature mortality on a global scale. Nature. 2015;525:367-71. 
44. Lepeule J, Laden F, Dockery D, Schwartz J. 2012. Chronic exposure to fine particles and mortality: an extended follow-up of the Harvard Six Cities study from 1974 to 2009. 120:7, 965-970.

45. Litovitz A, Curtright A, Abramzon S, Burger N, Samaras C. Estimation of regional air-quality damages from Marcellus Shale natural gas extraction in Pennsylvania. Environmental Research Letters. 2013;8:014017. (8 pp).

46. Liu M, Huanga Y, Ma Z, Jina Z, Liu X, Wang H, Liub Y, Wang J, Jantunen M, BiDra J, KinneyDr PL. Spatial and temporal trends in the mortality burden of air pollution in China: 2004-2012. Environ Int. 2017;98:75-81.

47. Lu X, Yaoa T, Fung JCH, Lin C. 2016. Estimation of health and economic costs of air pollution over the Pearl River Delta region in China. Science of the Total Environment. 566-567, 134-143.

48. Maji KJ, Dikshit AK, Arora M, Deshpande A. Estimating premature mortality attributable to PM2.5 exposure and benefit of air pollution control policies in China for 2020. Science of the Total Environment. 2018;612:683-93.

49. Mar TF, Koenig JQ, Primomo J. Associations between asthma emergency visits and particulate matter sources, including diesel emissions from stationary generators in Tacoma, Washington. Inhalation Toxicology. 2010;22(6):445-8.

50. Michanowicz DR, Williams SR, Buonocore JJ, Rowland ST, Konschnik KE, Goho SA, Bernstein AS. 2019. Population allocation at the housing unit level: estimates around underground natural gas storage wells in PA, OH, NY, WV, MI, and CA. Environmental Health. 18:58.

51. McKenzie LM, Allshouse WB, Burke T, Blair BD, Adgate JL. Population Size, Growth, and Environmental Justice near Oil and Gas Wells in Colorado. Environmental Science Technology. 2016;50:11471-80.

52. McKenzie LM, Witter RZ, Newman LS, Adgate JL. Human health risk assessment of air emissions from development of unconventional natural gas resources. Science of the Total Environment. 2012;424:79-87.

53. McKeon M. 2011. Horizontal Fracturing in Shale Plays (Workshop Presentation). Petroleum Transfer Technology Council. http://www.thepttc.org/workshops/eastern_062111/.

54. eastern_062111_McKeon.pdf; (accessed May 20, 2019).

55. Morellia X, Rieux C, Cyrys J, Forsberg B, Slama R. Air pollution, health and social deprivation: A finescale risk assessment. Environmental Research. 2016;147:59-70.

56. NAAQS. 2012. https://www.epa.gov/criteria-air-pollutants/naaqs-table; (accessed June 6, 2019).

57. National Cancer Institute. 2019. https://seer.cancer.gov/archive/csr/1975_2015/browse_.

58. csr.php? sectionSEL = 15\&pageSEL = sect_15_table.06; (accessed June 5, 2019).

59. Ostro B. Outdoor Air Pollution: Assessing the Environmental Burden of Disease at National and Local Levels. Environmental Burden of Disease Series, No. 5. Geneva: World Health Organization; 2004.

60. Pascal M, Chanel PC, Wagner V, Corso M, Tillier C, Bentayeb M, Blanchardc M, Cochet A, Pascal L, Hnct S Gnria S Tertre $\Delta I$ Chationnux F, Ung A, Beaudeau P, Medina S. The mortality impacts of fine Loading [MathJax]/jax/output/CommonHTML/jax.js 
particles in France. Science of the Total Environment. 2016;571:416-25.

61. Puett RC, Hart JE, Yanosky JD, Spiegelman D, Wang M, Fisher JA, Hong B, Laden F. Particulate Matter Air Pollution Exposure, Distance to Road, and Incident Lung Cancer in the Nurses'. Health Study Cohort. 2014;122(9):926-32.

62. Rabinowitz PM, Slizovskiy IB, Lamers V, Trufan SJ, Holford TR, Dziura JD, Peduzzi PN, Kane MJ, Reif JS, Weiss TR, Stowe MH. Proximity to Natural Gas Wells and Reported Health Status: Results of a Household Survey in Washington County, Pennsylvania. Environ Health Perspect. 2015;123(1):21-6.

63. Rasmussen SG, Ogburn EL, McCormack M, Casey JA, Bandeen-Roche K, Mercer DG, Schwartz BS. Association between Unconventional Natural Gas Development in the Marcellus Shale and Asthma Exacerbations. JAMA Internal Medicine. 2016;176(9):1334-43.

64. Roy AA, Adams PJ, Robinson AL. Air pollutant emissions from the development, production, and processing of Marcellus Shale natural gas. J Air Waste Manag Assoc. 2014;64(1):19-37.

65. International RTI. Environmental Benefits Mapping and Analysis Program (BenMAP) - Community Edition (User's Manual Appendices). Research Triangle Park: Office of Air Quality Planning and Standards, U.S. Environmental Protection Agency; 2015.

66. Shonkoff S, Hays J, Finkel ML. Environmental Public Health Dimensions of Shale and Tight Gas Development. Environ Health Perspectives. 2014;122(8):787-95.

67. Sovacool BK. Cornucopia or curse? Reviewing the costs and benefits of shale gas hydraulic fracturing (fracking). Renew Sustain Energy Rev. 2014;37:249-64.

68. Tustin AW, Hirsch AG, Rasmussen SG, Casey JA, Bandeen-Roche K, Schwartz BS. Associations between Unconventional Natural Gas Development and Nasal and Sinus, Migraine Headache, and Fatigue Symptoms in Pennsylvania. Environmental Health Perspectives. 2017;125(2):189-97.

69. Census Bureau US. 2012. https://www.census.gov/library/publications/timeseries/statistical_abstracts.html; (accessed June 5, 2019).

70. Weinbergera B, Greinerb LH, Walleighc L, Brown D. Health symptoms in residents living near shale gas activity: A retrospective record review from the Environmental Health Project. Preventive Medicine Reports. 2017;8:112-5.

71. Werner AK, Vink S, Watt K, Jagals P. Environmental health impacts of unconventional natural gas development: A review of the current strength of evidence. Science of the Total Environment. 2015;505:1127-41.

72. WHO. 2013. Health effects of particulate matter. World Health Organization.

73. WHO. 2007. Health relevance of particulate matter from various sources. Report on a WHO workshop, March 2007. World Health Organization: Bonn, Germany.

74. Xie W, Li G, Zhao D, Xie X, Wei Z, Wang W, Wang M, Li G, Liu W, Sun J, Jia Z, Zhang Q, Liu J. Relationship between fine particulate air pollution and ischaemic heart disease morbidity and mortality. Heart. 2015;101:257-63. 
75. Zanobetti A, Franklin M, Schwartz J. Fine particulate air pollution and its components in association with cause-specific emergency admissions. Environmental Health. 2009;8:58-60.

\section{Figures}

\begin{tabular}{|c|c|c|c|c|c|c|c|}
\hline \multicolumn{5}{|c|}{ Morbidity } & \multicolumn{3}{|c|}{ Mortality } \\
\hline 20411 & & & & & & & \\
\hline$\underline{64} \quad 810$ & $\frac{2208}{2151}$ & $\underline{157}$ & 485 & $\underline{84}$ & $\frac{32}{32}$ & $\underline{65}$ & $\frac{17}{7}$ \\
\hline 总悹 & 釆曾 & 3 & 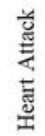 & 慁 & : & 3 & 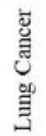 \\
\hline
\end{tabular}

\section{Figure 1}

Loading [MathJax]/jax/output/CommonHTML/jax.js 
Simulated changes in the incidence of health impacts due to shale gas activities (person). For the cases of asthma, chronic bronchitis and lung cancer, the lower and upper bounds are the estimated incidence cases based on available data for pollutant coefficients and baseline incidence rates. For other health impacts only one set of data was retrieved.

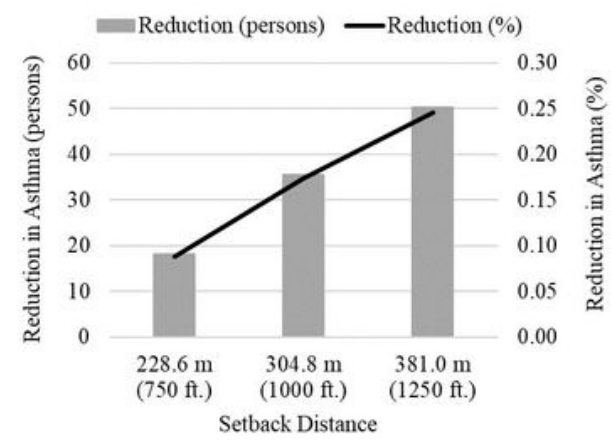

Figure 2

Loading [MathJax]/jax/output/CommonHTML/jax.js 
Estimated reduction in the number of asthma outcomes due to PM2.5 emissions from shale gas development at different setback distances compared to current setback distance in Pennsylvania (152.4 $\mathrm{m}$ or $500 \mathrm{ft}$.) for the case of Asthma.
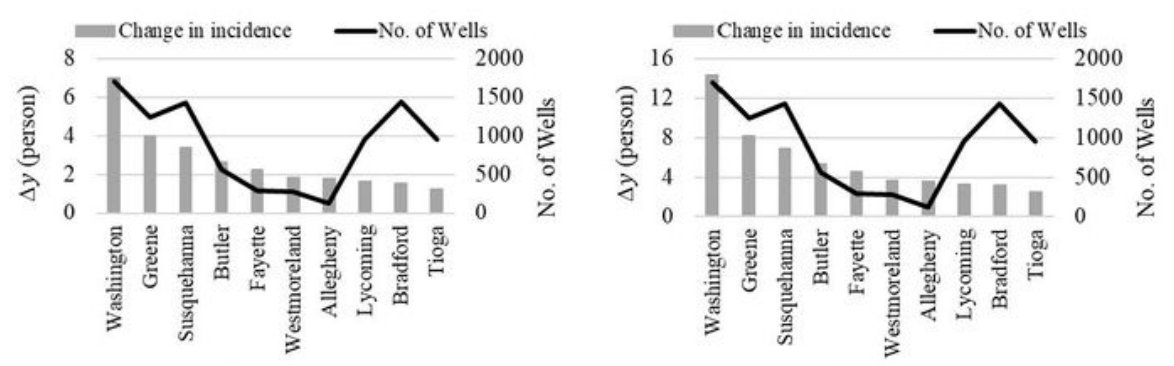

(a)

$\mathrm{CHD}$

(b)

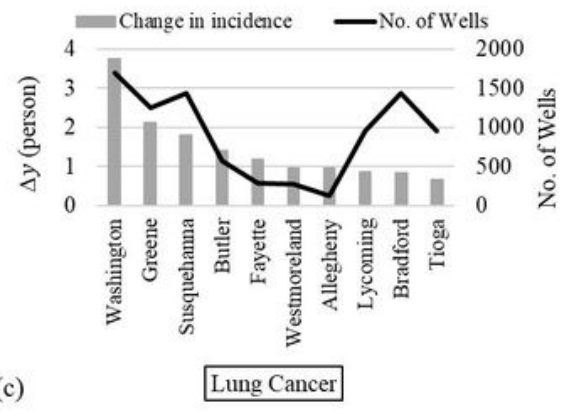

Figure 3

Simulated contribution of emissions from shale gas activities to changes in incidence of mortality Loading [MathJax]/jax/output/CommonHTML/jax.js ase (CHD), b) Cardiovascular disease (CVD), and c) Lung 
cancer.
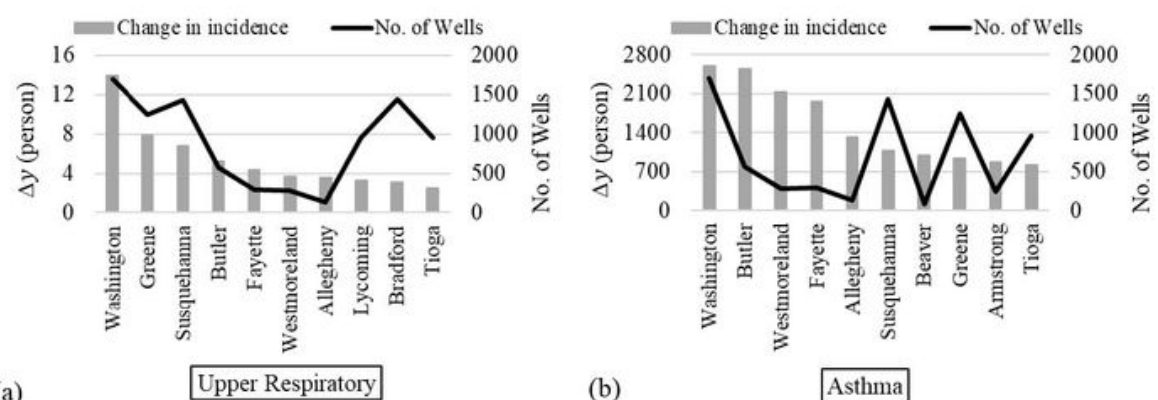

(a)

(b)

Asthma

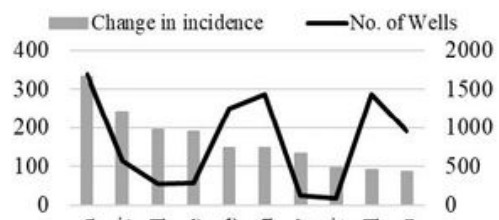

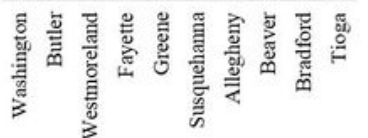

(c)

Chronic Bronchitis

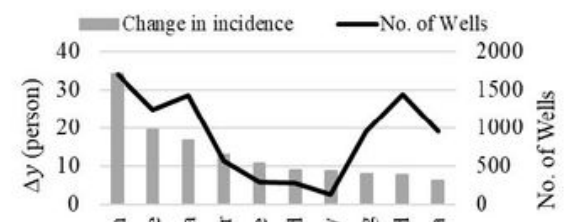

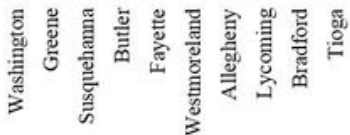

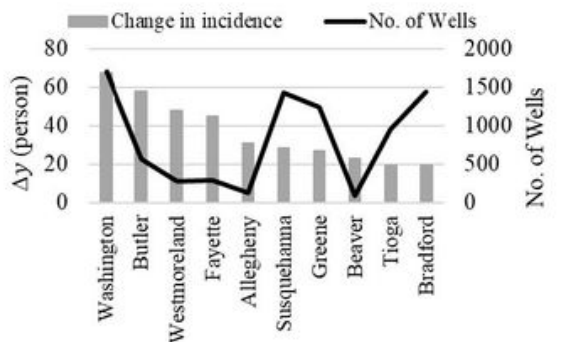

(e)

Heart Attack

(d)

CVD

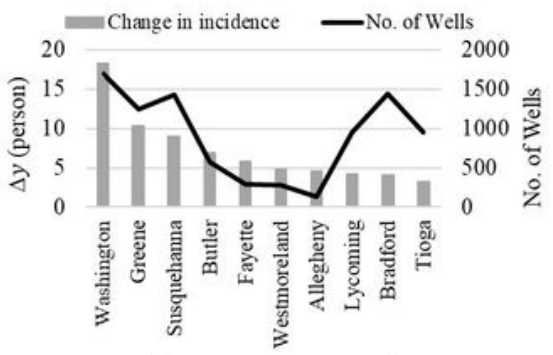

(f)

Ischemic Heart Disease

Figure 4

Simulated contribution of emissions from shale gas activities to changes in the number of morbidity outcomes by county: a) Acute upper respiratory disease, b) Asthma, c) Chronic bronchitis, d) Cardiovascular disease (CVD), e) Heart attack, and f) Ischemic heart disease (IHD). 


\section{Supplementary Files}

This is a list of supplementary files associated with this preprint. Click to download.

- AdditionalExcelFile.xIsx

- AdditionalTextFile.docx 